KREATIF : Jurnal Ilmiah Prodi Manajemen Universitas Pamulang, Vol. 8, No.2, Desember 2020

(GAPMMI),13 April 2020.

\title{
KREATIF \\ Jurnal IImiah
}

@ Prodi Manajemen Fakultas Ekonomi Universitas Pamulang

ISSN : 2339 - 0689, E-ISSN : 2406-8616

J. KREATIF, Vol. 8 No.2 Desember 2020 (Halaman 82-91)

Tersedia Online di :http://openjournal.unpam.ac.id/index.php/kreatif

\section{PENGARUH WORK SOCIAL SUPPORT TERHADAP CAREER SATISFACTION DENGAN CAREER ADAPTABILITY SEBAGAI VARIABEL MEDIASI PADA KARYAWAN BPJS KESEHATAN}

\author{
Yoshua $^{1}$,Yohanes Arianto Budi Nugroho \\ ${ }^{1-2}$ Unika Atma Jaya, Jakarta \\ email : yoshua190596@gmail.com,yohanes.arianto@atmajaya.ac.id
}

\begin{abstract}
ABSTRAK
Penelitian ini bertujuan untuk membuktikan apakah terdapat pengaruh dari work social support terhadap career satisfaction yang dimediasi oleh variabel career adaptability. Penelitian ini dilakukan di Kantor Pusat BPJS Kesehatan terhadap seluruh karyawan.

Penelitian ini menggunakan 170 responden sebagai sampel. Pengolahan data dilakukan secara terpisah terhadap responden laki - laki dan perempuan. Pengolahan data dilakukan dengan menggunakan software SPSS v22 dan macro Hayes PROCESS v3.

Dari hasil penelitian diketahui bahwa terdapat pengaruh yang positif dan signifikan antara work social support terhadap career adaptability, baik pada responden yang berjenis kelamin laki-laki maupun perempuan. Career adaptability menunjukkan pengaruh yang positif dan signifikan terhadap career satisfaction, baik pada responden laki-laki maupun perempuan. Work social support menunjukkan pengaruh yang positif dan signifikan terhadap career satisfaction, baik pada responden laki-laki maupun perempuan. Dan hasil penelitian juga menunjukkan bahwa career adaptability memediasi pengaruh antara work social support terhadap career satisfaction, baik pada responden laki-laki maupun pada responden perempuan di BPJS Kesehatan.
\end{abstract}

Kata Kunci : Work Social Support, Career Adaptability, Career Satisfaction

\section{ABSTRACT}

The purpose of this research is to inspect the impact of work social support on career satisfaction with the role of career adaptability as mediating variable. This research was conducted at the Head Office of Social Health Insurance Administration Organization involving all employees.

This research used 170 respondents as a sample. The data were processed separately between male and female respondents. The data were processed with SPSS v22 and macro Hayes PROCESS v3.

The findings showed significant and positive effect between work social support on career adaptability, on either male and female respondents. Career adaptability showed significant and positive effect on career satisfaction, on either male and female respondents. Work social support also showed significant and positive effect on career satisfaction, on either male and female respondents. And lastly, the mediation effect of career adaptability was tested among the effect between work social support on career 
KREATIF : Jurnal Ilmiah Prodi Manajemen Universitas Pamulang, Vol. 8, No.2, Desember 2020

satisfaction. The findings showed that career adaptability mediates the effect between work social support on career satisfaction, on either male and female respondents in the Head Office of Social Heatlh Insurance Administration Organization.

Keywords : Work Social Support, Career Adaptability, Career Satisfaction

\section{PENDAHULUAN}

\section{A. Latar Belakang Masalah}

Setiap karyawan menginginkan karier yang baik dalam pekerjaannya. Hal ini bisa dimulai dengan memilih tempat kerja dan posisi yang ditawarkan sesuai dengan keinginan. Hal lainnya dapat berupa dengan meningkatkan kualitas diri, seperti keahlian dan pendidikan, untuk meningkatkan kariernya pada jenjang yang lebih tinggi. Untuk itu, karyawan menentukan tujuan kariernya sejak awal sebelum memasuki tempat kerja agar tujuannya dapat tercapai. Ketika tujuan kariernya tidak tercapai atau terpenuhi, karyawan akan mengalami ketidakpuasan dalam karier pekerjaannya. Kepuasan karier dinilai sebagai sikap positif atau negatif yang dimiliki oleh individu terhadap pekerjaan mereka (Greenberg \& Baron, 2008). Sikap negatif individu terhadap karier yang dimiliki pada pekerjaan dapat berdampak pada beberapa hal, seperti komitmen, kinerja maupun niatan untuk meninggalkan pekerjaan yang ada dan mengganti pada pekerjaan yang baru dengan harapan dapat memenuhi tujuan kariernya.

Kepuasan karier yang dimiliki oleh karyawan dapat dipengaruhi oleh beberapa hal, seperti dukungan sosial kerja dan kemampuan beradaptasi pada karier. Hal ini merujuk pada penelitian yang dilakukan oleh Karatepe dan Olugbade (2017) yang berjudul "The Effects of Work Social Support and Career Adaptability on Career Satisfaction and Turnover Intentions" dan "The Relation of Career Adaptability to Satisfaction and Turnover Intentions" (Chan \& Mai, 2015). Pada penelitian ini menunjukkan bahwa dukungan sosial kerja dan kemampuan beradaptasi pada karier mempunyai pengaruh yang positif dan signifikan terhadap kepuasan karier. Dukungan dari rekan kerja dan atasan merupakan bagian penting dari sistem dukungan sosial kerja di tempat kerja dan memberi tanda bahwa ada lingkungan kerja yang berfokus kepada karyawan (Karatepe, 2013). Sedangkan kemampuan beradaptasi pada karier terdiri dari empat dimensi, yaitu perhatian, kontrol, rasa ingin tahu, dan kepercayaan diri. Individu yang mudah beradaptasi dikonseptualisasikan sebagai perhatian tentang masa depan, mengambil kendali untuk mencoba mempersiapkan masa depan, menunjukkan rasa ingin tahu dengan mengekspolrasi kemungkinan diri dan potensi masa depan, dan memperkuat kepercayaan diri untuk mengejar aspirasi (Savickas \& Porfeli, 2012).

Ketika individu bekerja di lingkungan yang mendukung yang mencakup dukungan yang timbul dari rekan kerja dan atasan, dan mampu membangun karier mereka dengan memanfaatkan sumber daya yang diperlukan untuk beradaptasi dengan kariernya, mereka cenderung memberikan hasil afektif seperti kepuasan karier (Karatepe \& Uludag, 2008). Secara singkat, dapat dijelaskan bahwa kemampuan beradaptasi pada karier adalah mekanisme yang mendasari hubungan dukungan sosial kerja dengan kepuasan karier. Untuk itu, karyawan memerlukan dukungan sosial kerja dari rekan kerja dan atasan pada tempat kerja dan kemampuan beradaptasi pada karier secara individu dengan baik demi tercapainya kepuasan karier. Dengan tercapainya kepuasan karier, dampak-dampak yang bisa timbul dari ketidakpuasan karier dapat dihindari. 
KREATIF : Jurnal Ilmiah Prodi Manajemen Universitas Pamulang, Vol. 8, No.2, Desember 2020

Badan Penyelenggara Jaminan Sosial (BPJS) adalah sebuah lembaga yang dibentuk untuk menyelenggarakan program jaminan sosial di seluruh Indonesia menurut UndangUndang No. 40 Tahun 2004 dan Undang-Undang No. 24 Tahun 2011. Berdasarkan Undang-Undang No. 40 Tahun 2004 tentang sistem jaminan sosial nasional, BPJS adalah sebuah badan hukum nirlaba. Berdasarkan Undang-Undang No. 24 Tahun 2011, BPJS menggantikan peran sejumlah lembaga jaminan sosial yang ada di Indonesia. Lembaga asuransi jaminan kesehatan PT Askes Indonesia beralih menjadi BPJS Kesehatan dan lembaga jaminan sosial ketenagakerjaan PT Jamsostek beralih menjadi BPJS Ketenagakerjaan. Transformasi PT Askes dan PT Jamsostek menjadi BPJS dilakukan secara bertahap. Pada awal tahun 2014, PT Askes beralih menjadi BPJS Kesehatan. Sedangkan pada tahun 2015, PT Jamsostek menjadi BPJS Ketenagakerjaan. Lembaga ini bertanggung jawab langsung terhadap Presiden.

BPJS Kesehatan bertugas memberikan jaminan kesehatan bagi seluruh masyakarat Indonesia. Dengan tugas yang sangat besar dampak dan manfaatnya bagi masyarakat, maka diperlukan pelayanan yang sangat baik. Berbeda dengan bekerja di perusahaan ataupun korporasi swasta yang memiliki jenjang karier yang jelas dan lebih menjanjikan, bekerja di badan milik pemerintah yang bukan perusahaan miliki negara atau Badan Usaha Milik Negara (BUMN) yang tujuannya tidak mencari keuntungan, tetapi berfokus kepada pelayanan masyarakat, menjadikan berkarier di badan milik pemerintah ini kurang menjanjikan dari segi karier. Dan untuk menjaga agar kondisi ini tidak berdampak pada rendahnya kepuasan karier karyawan, maka dukungan sosial kerja dari rekan kerja maupun atasan, serta kemampuan beradaptasi pada karier yang baik menjadi penting agar kepuasan karier karyawan tetap terjaga dengan baik. Karena itu, peneliti tertarik untuk melakukan penelitian dengan menetapkan judul "Pengaruh Work Social Support terhadap Career Satisfaction dengan Career Adaptability sebagai Variabel Mediasi pada BPJS Kesehatan"

\section{TINJUAN PUSTAKA}

\section{A. Work Social Support}

Carlson dan Perrewe (1999), menyatakan bahwa Work social support merupakan suatu transaksi interpersonal yang melibatkan perhatian emosional, bantuan instrumental, informasi, atau penilaian. Work social support terdiri dari co-worker dan supervisor support. Definisi Co-worker support adalah sebuah ketersediaan dukungan dari rekan kerja yang dirasakan oleh individu saat membutuhkannya (Lane, 2004). Sedangkan definisi supervisor support adalah suatu sudut pandang karyawan terhadap atasan mereka dalam menilai kontribusi mereka terhadap organisasinya serta kepedulian atasan tersebut terhadap kesejahteraan mereka (Rhoades et al., 2001).

\section{B. Career Adaptability}

Savickas dan Porfeli (2012), menyatakan bahwa career adaptability adalah suatu kesiapan seseorang untuk menyelesaikan tugasnya yang sudah terprediksi dan ikut berpartisipasi dalam peran pekerjaan, serta mampu menguasai situasi tidak terduga yang mungkin terjadi karena perubahan dalam pekerjaan dan kondisi kerja. Career adaptability memungkinkan seorang individu siap dan mengatasi tugas perkembangan, transisi pekerjaan, dan trauma pekerjaan. Savickas dan Porfeli (2012) merumuskan empat dimensi yang digunakan untuk mengukur career adaptability. Skala ini mengukur empat sumber daya psikososial karyawan untuk mengelola pengembangan karier mereka. Empat dimensi 
KREATIF : Jurnal Ilmiah Prodi Manajemen Universitas Pamulang, Vol. 8, No.2, Desember 2020

dari career adaptability, yaitu : (a) career concern, career control, career curiousity, dan career confidence.

\section{Career Satisfaction}

Career satisfaction didefinisikan oleh Robbins dan Judge (2009) sebagai suatu perasaan positif tentang pekerjaan seseorang yang merupakan hasil dari evaluasi karateristiknya. Sedangkan menurut Greenberg (2008), career satisfaction adalah sebuah sikap positif atau negatif yang dimiliki individu terhadap pekerjaan mereka. Menurut Yap, Cukier, Holmes, dan Hannan (2010), career satisfaction merupakan pengukuran yang bersifat subjektif dari kesuksesan karier (objektif dan subjektif) yang menangkap persepsi kepuasannya dengan keseluruhan tujuan karier yaitu tujuan untuk pendapatan, tujuan untuk kemajuan, dan tujuan untuk perkembangan kemampuan baru. Tujuan, persepsi kerja, dan faktor demografi mempengaruhi tingkat kepuasan karier karyawan. Menurut Payakachat, Ounpraseuth, Ragland, dan Murawski (2011), career satisfaction berhubungan erat dengan kehidupan pekerjaan dan hal itu akan membuat seseorang tidak akan berhenti dari pekerjaannya.

\section{Work Social Support dan Career Adaptability}

Co-worker support mengacu pada kepeduliaan dan pertimbangan yang diterima karyawan dari anggota lain dalam organisasi (Mossholder, Settoon, \& Henagan, 2005). Jumlah bantuan yang karyawan rasakan dari rekan kerjanya akan membantu mereka untuk dapat berperilaku adaptif mengenai karier mereka. Supervisor support didefinisikan sebagai keyakinan individu bahwa atasan menawarkan kepada mereka bantuan terkait pekerjaan untuk membantu dalam kinerja pekerjaan mereka (Susskind, Kacmar, \& Borchgrevink, 2003). Ketersediaan dukungan atasan mengirimkan sinyal kepada karyawan bahwa atasan mendengarkan permasalah karyawan di tempat kerja, mendorong mereka tentang akusisi keterampilan, pengembangan dan kemajuan karier, dan bertukar pendapat dan ide (Ito \& Brotheride, 2005). Ketika karyawan menemukan bahwa mereka mendapatkan dukungan emosional dan instrumental yang cukup dari rekan kerja dan atasan mereka selain kekuatan atau kapasitas regulasi mandiri mereka, mereka dapat fokus pada rencana karier dan memantau kemajuan kariernya.Berdasarkan penelitian terhadap pegawai sipil federal Kanada, Ito and Brotheridge (2005) menemukan bahwa kehadiran supervisor support mendorong career adaptability karyawan. Sedangkan, penelitian yang dilakukan Creed et al. (2009), ditemukan bahwa dukungan sosial berhubungan positif dengan career adaptability. Hirschi (2009), menunjukkan bahwa dukungan sosial mendorong career adaptability pada siswa di Swiss.

\section{E. Career Adaptability dan Career Satisfaction}

Maggiori, Johnston, Krings, Massoudi, dan Rossier (2013) melakukan penelitian dikalangan orang tua yang bekerja maupun yang tidak bekerja di Swiss dan hasilnya menunjukkan bahwa career adaptability meningkatkan kesejahteraan umum (seperti kepuasan hidup) dan kesejahteraan profesional (kepuasan kerja). Pada penelitian lainnya, mengungkapkan bahwa karyawan yang lebih tinggi dalam pengalaman beradaptasi mengalami kepuasan lebih dengan karier mereka (Niu and Guo, 2009).

\section{F. Work Social Support dan Career Satisfaction}

Supervisor support yang diberikan dalam bentuk bimbingan karier dan informasi, umpan balik kinerja, penyediaan tugas menantang yang mempromosikan pengembangan 
KREATIF : Jurnal Ilmiah Prodi Manajemen Universitas Pamulang, Vol. 8, No.2, Desember 2020

karier, penerimaan, persahabatan, dan konseling dapat memperkaya karier karyawan. Diskusi semacam ini tampaknya berlaku untuk dukungan yang muncul dari rekan kerja. Co-worker support dapat berkontribusi pada karier karyawan melalui bimbingan dan informasi karier, pengembangan keterampilan baru, dan persahabatan. Hubungan yang mendukung seperti itu juga dapat meningkatkan kepuasan karyawan dengan karier mereka di organisasi saat ini (Karatepe \& Olugbade, 2017). Ketika karyawan menemukan bahwa mereka mampu mengelola masalah yang berhubungan dengan pekerjaan mereka dan menangani perkembangan karier mereka dan kemajuan melalui dukungan emosional dan juga instrumental yang diperoleh dari rekan kerja dan atasan, mereka puas dengan karier mereka (Karatepe \& Olugbade, 2017). Berdasarkan penelitian Kang, Gatling, \& Kim (2015), menemukan bahwa supervisor support menghasilkan career satisfaction karyawan hotel.

\section{G. Work Social Support, Career Adaptability, Career Satisfaction}

Dukungan sosial adalah sumber pekerjaan penting yang memungkinkan karyawan untuk mengelola karier mereka dengan sukses (Yarnall, 1998). Penelitian Hirschi, Niles, dan Akos (2011) mendukung pernyataan ini. Secara khusus, mereka telah mendokumentasikan bahwa ketersediaan dukungan sosial memungkinkan individu untuk lebih terlibat dalam persiapan karier. Dukungan sosial di tempat kerja juga diperlukan sebagai sumber daya yang menggerakan adaptasi karier karyawan. Karyawan dengan dukungan sosial yang cukup di tempat kerja cenderung memiliki kemampuan adaptasi karier yang tinggi (Ito \& Brotheridge, 2005). Work social support telah dibuktikan dapat mengaktifkan career satisfaction karyawan (Kang et al., 2015). Career adaptability juga telah ditunjukkan dapat menstimulasi career satisfaction (Guan, Zhou, Ye, Jiang, \& Zhou, 2015). Singkatnya, career adaptability berperan memediasi hubungan antara work social support dan career satisfaction.

\section{METODE PENELITIAN}

\section{A. Populasi dan sampel}

Populasi dari penelitian ini adalah karyawan kantor pusat BPJS Kesehatan yang jumlahnya 548 karyawan. Menurut teori Roscoe dalam Sekaran (2003), ukuran sampel yang ideal adalah antara 30 sampai dengan 500 objek penelitian. Sehingga, peneliti menggunakan 170 karyawan sebagai sampel penelitian. Pengambilan sampel menggunakan metode non probability sampling, yaitu metode pengambilan sampel dengan kondisi probabilita yang tidak setara dari setiap anggota sampel yang diteliti, untuk teknik pengumpulan data menggunakan teknik convenience sampling, yaitu pengambilan sampel berdasarkan ketersediaan elemen tersebut dan kemudahan untuk mendapatkannya (Noor, 2011).

Untuk mengukur variabel work social support, penelitian ini menggunakan indikator yang disusun oleh Hammer, Saksvik, Nytro, Torvatn, dan Bayazit (2004) untuk co-worker support yang dimuat dalam Journal of Management \& Organization pada tahun 2017, sedangkan untuk supervisor support menggunakan indikator yang disusun oleh Kianto (2008) dalam ORCI Survey yang dimuat dalam Leadership \& Organization Development Journal pada tahun 2015. Untuk mengukur variabel career adaptability, menggunakan career adapt-abilities inventory-international version dari Savickas dan Porfeli (2012) yang dimuat dalam Journal of Management \& Organization pada tahun 2017. Sedangkan variabel career satisfaction menggunakan indikator yang disusun oleh Martins et al., 
KREATIF : Jurnal Ilmiah Prodi Manajemen Universitas Pamulang, Vol. 8, No.2, Desember 2020

(2002); Dacre Pool dan Qualter (2013) yang dimuat dalam International Journal of Contemporary Hospitality Management pada tahun 2016.

Gambar 1. Model penelitian untuk responden Laki-laki

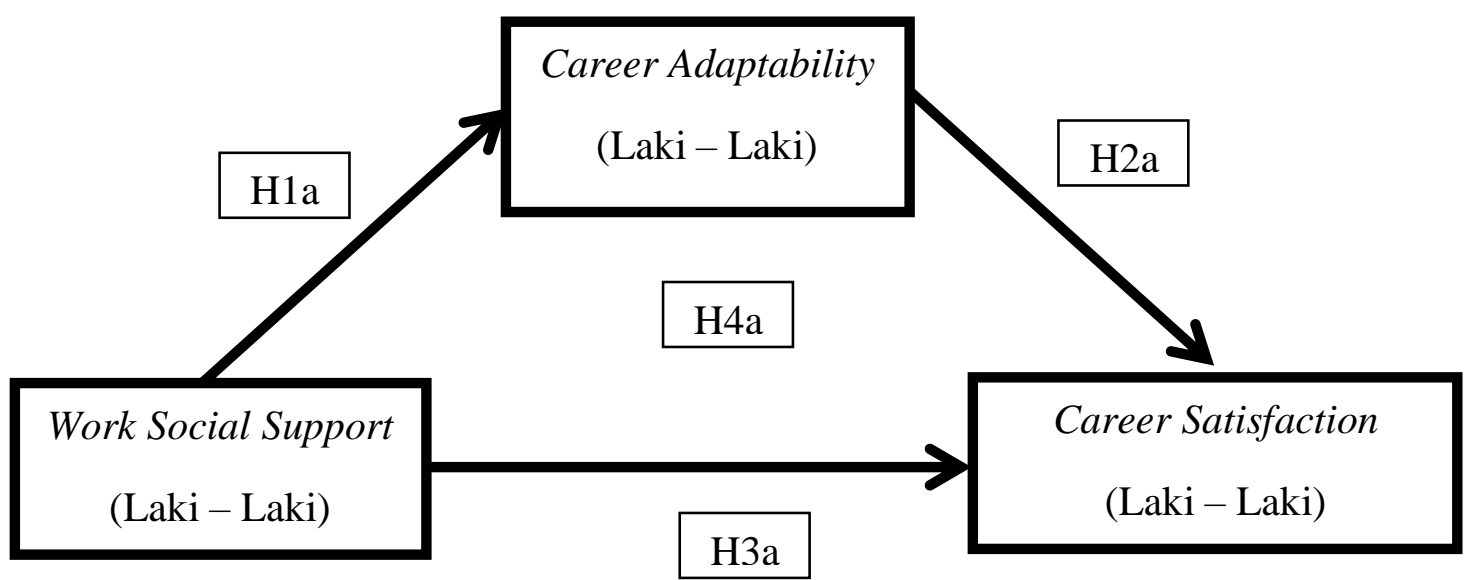

Gambar 2.. Model penelitian untuk responden Perempuan

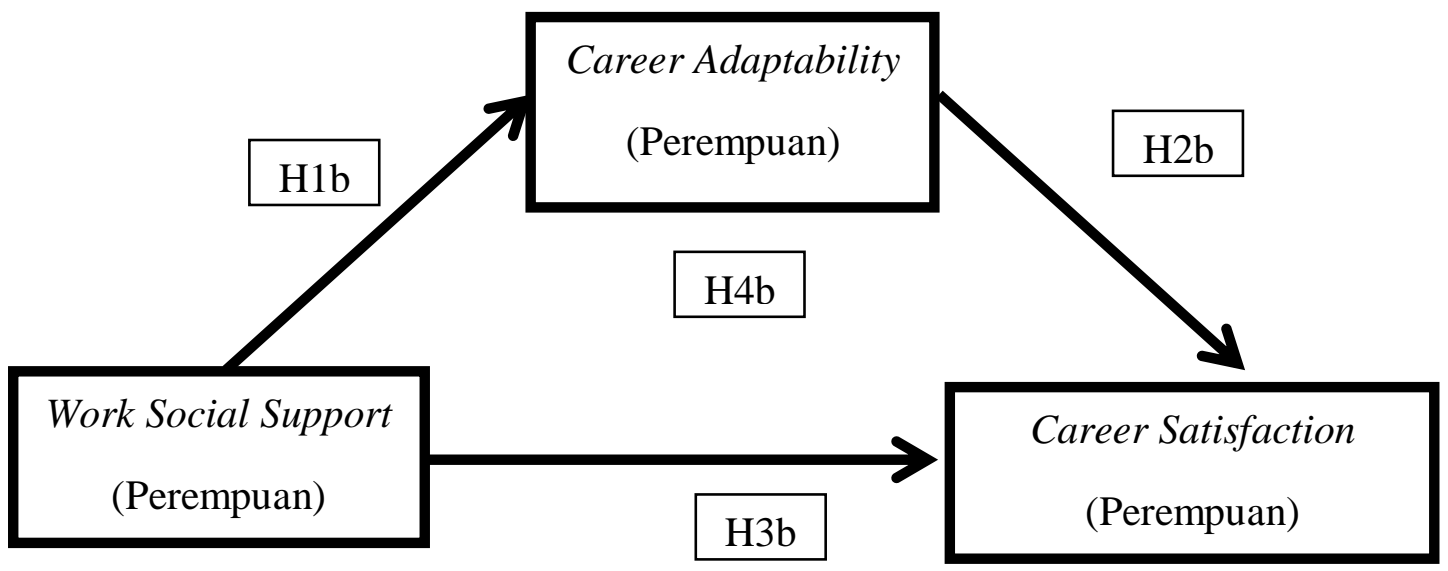

\section{B. Hipotesis penelitian}

H1a : Work Social Support berpengaruh terhadap Career Adaptability (CAD) pada karyawan laki-laki di BPJS Kesehatan.

H2a : Career Adaptability berpengaruh terhadap Career Satisfaction pada karyawan lakilaki di BPJS Kesehatan.

H3a : Work Social Support berpengaruh terhadap Career Satisfaction pada karyawan lakilaki di BPJS Kesehatan.

H4a : Work Social Support(WSS) berpengaruh terhadap Career Satisfaction dengan Career Adaptability sebagai variabel mediasi pada karyawan laki-laki di BPJS Kesehatan.

H1b : Work Social Support berpengaruh terhadap Career Adaptability pada karyawan perempuan di BPJS Kesehatan.

$\mathrm{H} 2 \mathrm{~b}$ : Career Adaptability berpengaruh terhadap Career Satisfaction pada karyawan perempuan di BPJS Kesehatan. 
KREATIF : Jurnal Ilmiah Prodi Manajemen Universitas Pamulang, Vol. 8, No.2, Desember 2020

H3b : Work Social Support berpengaruh terhadap Career Satisfaction pada karyawan perempuan di BPJS Kesehatan.

H4b : Work Social Support berpengaruh terhadap Career Satisfaction dengan Career Adaptability sebagai variabel mediasi pada karyawan perempuan di BPJS Kesehatan.

\section{HASIL DAN PEMBAHASAN}

\section{A. Hasil Penelitian}

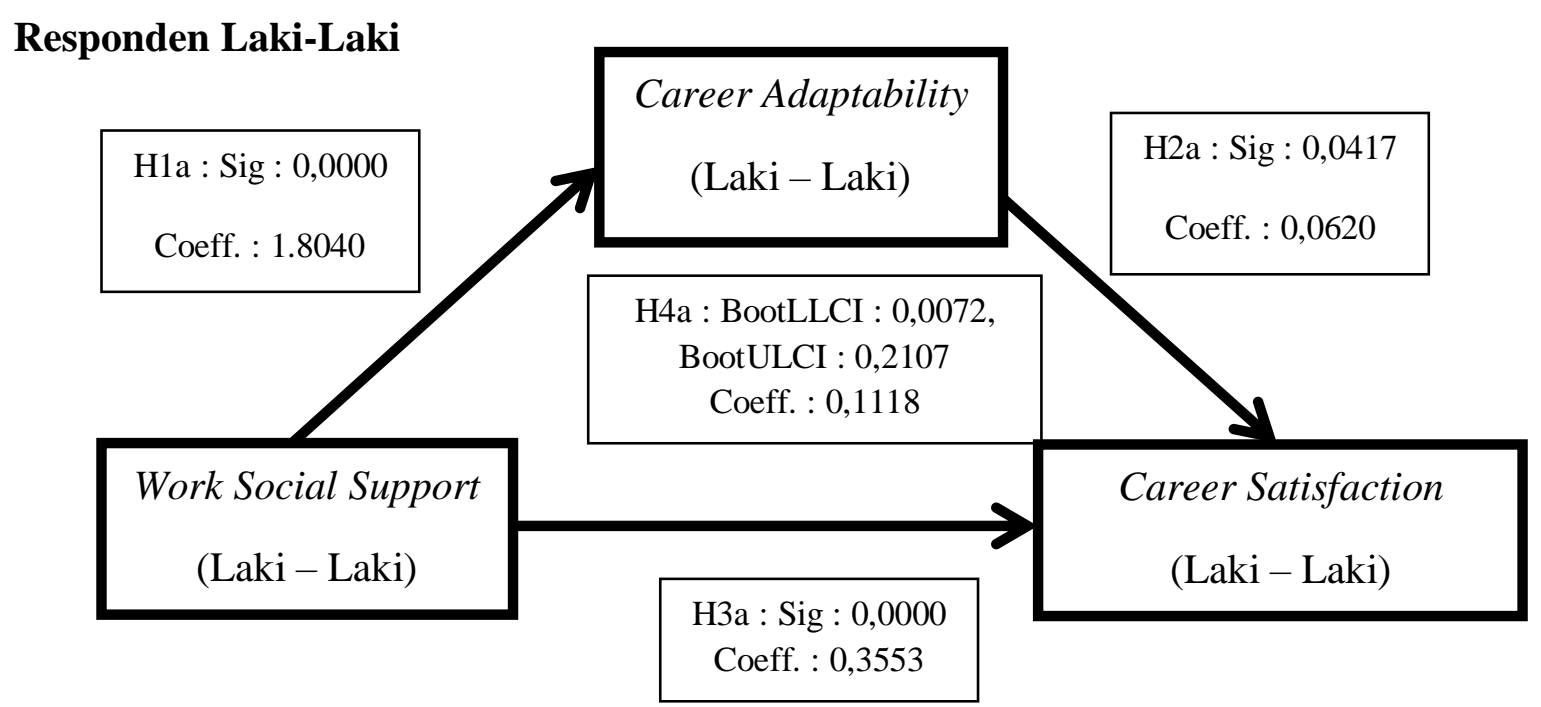

\section{Responden Perempuan}

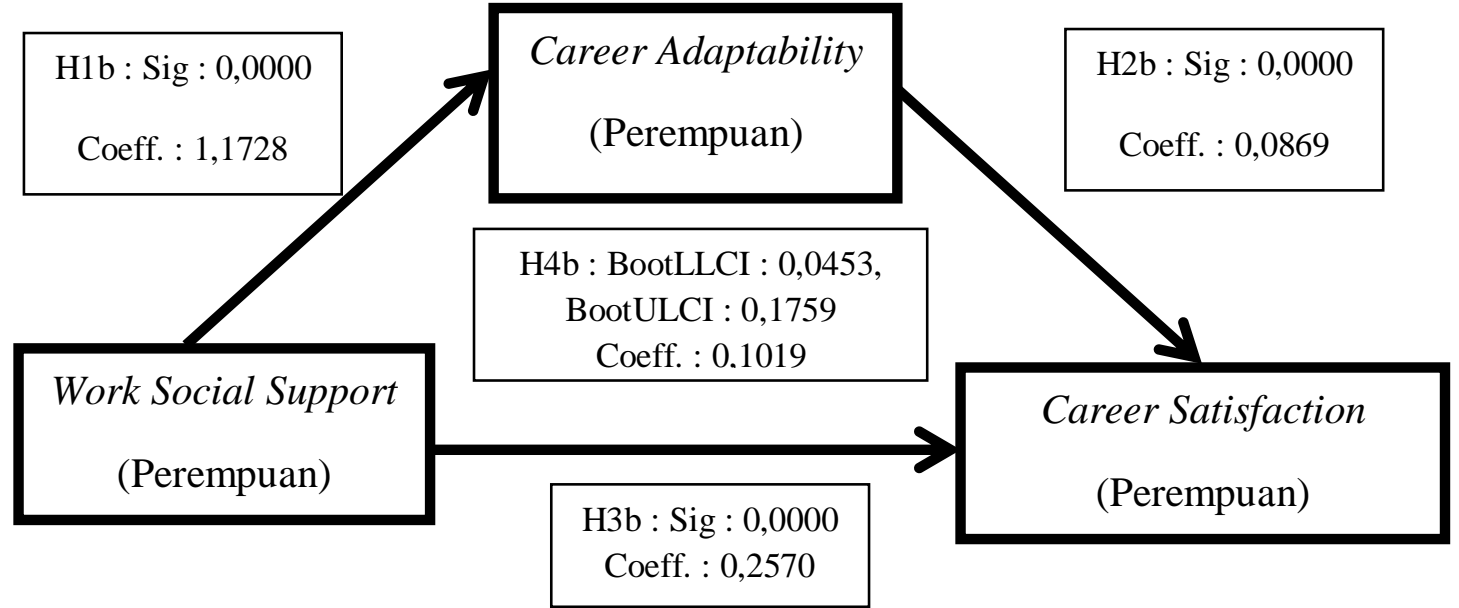

\section{B. Pembahasan}

Hasil pengolahan data di atas menunjukkan bahwa pada responden laki-laki nilai $\mathrm{p}=$ $0,0000<\alpha=0,05$, sehingga dapat disimpulkan bahwa work social support berpengaruh secara signifikan terhadap career adaptability. Sehingga Hipotesis 1a diterima. 
KREATIF : Jurnal Ilmiah Prodi Manajemen Universitas Pamulang, Vol. 8, No.2, Desember 2020

Hasil perhitungan selanjutnya menunjukkan bahwa pada responden laki-laki nilai $\mathrm{p}=$ $0,0417<\alpha=0,05$ untuk $C A D$ dan $\mathrm{p}=0,0000<\alpha=0,05$ untuk WSS, artinya terdapat pengaruh yang signifikan untuk career adaptability terhadap career satisfaction dan work social support terhadap career satisfaction pada responden laki - laki. Sehingga Hipotesis $\underline{\text { 2a }}$ dan Hipotesis 3a diterima.

Pada responden laki-laki, career adaptability memediasi pengaruh antara work social support terhadap career satisfaction karena antara nilai BootLLCI dan BootULCI tidak melewati angka 0 (BootLLCI $=0,0072$ dan BootULCI $=0,2107)$.Sehingga Hipotesis 4a diterima.

Dari hasil pengolahan data pada responden perempuan menunjukkan bahwa nilai $\mathrm{p}=$ $0,0000<\alpha=0,05$, sehingga dapat disimpulkan bahwa work social support berpengaruh secara signifikan terhadap career adaptability. Sehingga Hipotesis 1b diterima. Dari hasil perhitungan di atas menunjukkan bahwa nilai $\mathrm{p}=0,0010<\alpha=0,05$ untuk $C A D$ dan $\mathrm{p}=$ $0,0000<\alpha=0,05$ untuk WSS pada responden perempuan, yang artinya terdapat pengaruh yang signifikan untuk career adaptability terhadap career satisfaction dan work social support terhadap career satisfaction pada responden perempuan. Sehingga Hipotesis 2b dan Hipotesis $\mathbf{3 b}$ diterima.

Data di atas menunjukkan bahwa pada responden perempuan, career adaptability memediasi pengaruh antara work social support terhadap career satisfaction karena antara nilai BootLLCI dan BootULCI tidak melewati angka 0 (BootLLCI $=0,0453$ dan BootULCI = 0,1759).Sehingga Hipotesis 4b diterima.

\section{KESIMPULAN DAN SARAN}

Meskipun kedua model persamaan tersebut sama-sama menunjukkan adanya mediasi dari variabel Career Adaptability, namun pengaruh yang sebenarnya adalah pengaruh langsung. Hal ini dapat kita lihat pada responden laki-laki dengan nilai koefisien mediasi $(0,111)$ yang lebih kecil dari koefisien pengaruh langsung $(0,3553)$. Demikian juga pada responden perempuan yang koefisien mediasinya $(0,1)$ juga lebih kecil dari koefisien pengaruh langsung $(0,2570)$. Terdapat beberapa saran yang diberikan oleh peneliti berdasarkan hasil penelitiannya yaitu :

1. Dengan tingkat work social support yang berada pada tingkat yang tinggi, maka BPJS Kesehatan diharapkan dapat mempertahankan keadaan ini. Hal ini dapat ditingkatkan dengan memastikan sesama karyawan mengerti jika rekan kerjanya sedang mengalami hari yang buruk. Dan juga memastikan supervisor memahami dan mengetahui kebutuhan dan tujuan karyawannya.

2. Dengan tingkat career adaptability yang berada pada tingkat yang tinggi, maka BPJS Kesehatan diharapkan dapat mempertahankan keadaan ini. Hal ini dapat ditingkatkan dengan memastikan keingintahuan yang dimiliki karyawan tetap terus ada.

3. Dengan tingkat career satisfaction yang berada pada tingkat yang tinggi, maka BPJS Kesehatan diharapkan dapat mempertahankan keadaan ini. Hal ini dapat ditingkatkan dengan memastikan karyawan memiliki rasa terikat secara emosional dengan kariernya dan juga memastikan kepuasan perkembangan karier secara keseluruhan. 
KREATIF : Jurnal Ilmiah Prodi Manajemen Universitas Pamulang, Vol. 8, No.2, Desember 2020

4. Dalam meningkatkan career satisfaction karyawan, BPJS Kesehatan sebaiknya memperhatikan kedua variabel yang mempengaruhi variabel tersebut, yaitu variabel work social support dan career adaptability.

\section{DAFTAR PUSTAKA}

Carlson, D. S. \&amp; Perrewé, P. L. (1999). The Role Of Social Support In The StressorStrain Relationship: An Examination Of Work-Family Conflict. Journal of Management, 25(4), 513-540.

Chan, S. H. J., \&amp; Mai, X. (2015). The Relation Of Career Adaptability To Satisfaction And Turnover Intentions. Journal of Vocational Behavior, 89, 130-139.

Creed, P. A., Fallon, T., \&amp; Hood, M. (2009). The Relationship Between Career Adaptability,Person And Situation Variables, And Career Concerns In Young Adults. Journal of Vocational Behavior, 74(2), 219-229.

Pool, D., Lorraine, \&amp; Qualter, P. (2013). Emotional Self-Efficacy, Graduate Employability, And Career Satisfaction: Testing The Associations. Australian Journal of Psychology, 65(4), 214-223.

Greenberg, J. \&amp; Baron, R. A. (2008). Behavior in Organizations (9th ed.). New Jersey: Pearson Education.

Guan, Y., Zhou, W., Ye, L., Jiang, P., \&amp; Zhou, Y. (2015). Perceived Organizational Career

Management And Career Adaptability As Predictors Of Success And Turnover Intention Among Chinese Employees. Journal of Vocational Behavior, 88, 230-237.

Hirschi, A., Niles, S. G., \&amp; Akos, P. (2011). Engagement In Adolescent Career Preparation: Social Support, Personality And The Development Of Choice Decidedness $\quad$ And Congruence. Journal of Adolescence, 34(1), 173- 182.

Ito, J. K. \&amp; Brotheridge, C. M. (2005). Does Supporting Employees \&\#39; Career Adaptability Lead To Commitment, Turnover, Or Both?. Human Resource Management, 44(1), 5-19.

Kang, H. J., Gatling, A., \&amp; Kim, J. (2015). The Impact Of Supervisory Support On Organizational Commitment, Career Satisfaction, And Turnover Intention For Hospitality Frontline Employees. Journal of Human Resources in Hospitality \&amp; Tourism, 14(1), 68-89.

Karatepe, O. M. (2013). High-Performance Work Practices, Work Social Support And Their Effects On Job Embeddedness And Turnover Intentions. International Journal of Contemporary Hospitality Management, 25(6), 903-921.

Karatepe, O. M., \&amp; Uludag, O. (2008). Supervisor Support, Work-Family Conflict, And Satisfaction Outcomes: An Empirical Study In The Hotel Industry. Journal of Human Resources in Hospitality \&amp; Tourism, 7(2), 115-134.

Karatepe, O. M., \&amp; Olugbade, O. A. (2017). The Effects Of Work Social Support And Career Adaptability On Career Satisfaction And Turnover Intentions. Journal of Management \&amp; Organization, 23(3), 337-355.

Kianto, A. (2008). Development And Validation Of A Survey Instrument For Measuring Organisational Renewal Capability. International Journal of Technology Management, 42(1-2), 69-88. 
KREATIF : Jurnal Ilmiah Prodi Manajemen Universitas Pamulang, Vol. 8, No.2, Desember 2020

Lane, R. S. (2004). The Influence Of Work Stress And Work Support On Burnout In Public Hospital Nurses. Unpublished Doctoral Dissertation, Faculty of Education, Queensland University of Technology, Australia.

Maggiori, C., Johnston, C. S., Krings, F., Massoudi, K., \&amp; Rossier, J. (2013). The Role Of Career Adaptability And Work Conditions On General And Professional Well- Being. Journal of Vocational Behavior, 83(3), 437- 449.

Martins, L.L., Eddleston, K.A., and Viega, J.F. (2002). Moderators Of The Relationship Between

Work-Family Conflict And Career Satisfaction. Academy of Management Journal, Vol. $\quad 45$ No.2, pp.399-409. 